\title{
Identifying the Key Concerns of Irish Persons with Intellectual Disability
}

\author{
Edurne García Iriarte*, Patricia O’Brien ${ }^{\dagger}$, Roy McConkey ${ }^{\ddagger}$, Marie Wolfe ${ }^{\S}$ and Siobhain O’Doherty ${ }^{\Uparrow}$ \\ *National Institute for Intellectual Disability, Trinity College Dublin, Dublin, Ireland; 'University of Sydney, Sydney, NSW, Australia; ${ }^{\star} U$ Ulster \\ University, Newtownabbey, UK; ${ }^{\S}$ Brothers of Charity Galway \& Inclusive Research Network, Galway, Ireland; "Trinity College Dublin, Dublin, \\ Ireland
}

Accepted for publication 12 April 2014

Background Internationally, people with intellectual disability are socially marginalized, and their rights under the United Nations Convention for the Rights of Persons with Disabilities (CRPD) are often ignored.

Aims This paper aims to define the key concerns of adults with an intellectual disability in relation to their participation in society using an inclusive research strategy for both data gathering and data analysis.

Methods A national study involving 23 focus groups and 168 persons was conducted on the island of Ireland with people with intellectual disability as co-facilitators. Findings A thematic content analysis was undertaken of the verbatim transcripts initially by university coresearchers, and 19 themes were identified. Co-researchers with intellectual disability joined in identifying the eight core themes. These were as follows: living options, employment, relationships, citizenship, leisure time, money management, self-advocacy, and communication. Discussion The concerns are discussed within the framework of the CRPD, and implications for transforming service policy are drawn.

Keywords: inclusive research, intellectual disability, Ireland, national survey

\section{Accessible Abstract}

Why we did the research In many countries, people with intellectual disability have difficulties doing things other people without disabilities do, for example to study, to get a job or to live independently. They also find that their rights are not respected under the Convention on the Rights of Persons with Disabilities (the Convention).

We did this study to

- Learn what are the main issues for adults with intellectual disability in Ireland.

- Do research with people with intellectual disability. How we did the research People with intellectual disability and their supporters worked with university researchers to plan and do the research. We met with people in groups and 168 people told us about things important to them.

What we found out We found that there were very important things that people talked about in the groups. We chose the most important: living options, employment, relationships, rights, leisure, money, selfadvocacy, and communication. We talk about the Convention and why things people told us are important for services.

\section{Introduction}

The most recent estimates identify that one per cent of the worldwide population live with an intellectual disability which not only impacts on the disabled person but their families and communities (Maulik et al. 2011). Due to increased longevity of the general population and longer life expectancy of persons with this disability, this number is rising (IASSID 2002; McCarron \& Lawlor 2003).

The United Nations Convention on the Rights of Persons with Disabilities (CRPD; UN 2006) and the European Disability Strategy 2010-2020 (European Union 2010) have at their core the right of all persons to be treated on an equal basis with others, to live independently in community settings and to access 
education and employment. However, this necessitates a major transformation in the way services for persons with intellectual disability are provided in many countries. For example, in the Republic of Ireland, around $75 \%$ of the annual budget is allocated to residential and day care services and only a quarter is available for other forms of service provision, such as employment supports, further education, independent living and personal assistants [National Disability Authority (NDA) 2010a].

At the core of the reformation of services must be the recognition of people with intellectual disability as full persons before the law (Quinn 2009) and the recognition of their will and preferences, which allow for the differentiation between objective outcomes (e.g. employment, income) and subjective outcomes (e.g. satisfaction with services, quality of life) (NDA 2010b). There are, however, relatively few examples of national studies that have explored preferences of people with intellectual disability. The most ambitious - and by far the most costly - was that undertaken in England which was based on 2898 individual interviews mostly with the person with intellectual disability as the informant - although proxy responses were also included (Emerson et al. 2005). Likewise in Scotland, a postal survey involving 605 informants was undertaken although this methodology may have limited the sample to those who had literacy skills (Curtice 2006). In New Zealand, focus groups were used to gather the views of around 100 persons in different localities around the country (Logan et al. 2003). A study undertaken in Croatia (Association for Self-Advocacy Croatia 2007) exemplifies an inclusive research approach in which self-advocates interviewed a sample of 88 persons with intellectual disability.

Comparison of previous studies shows some similarities and disparities on the concerns expressed by people across Croatia, England, Scotland and New Zealand. The main concerns identified across all countries included choice of living place, control over money, employment, health, citizenship and transport. However, these concerns were experienced differently in each country, probably reflecting the range of services and supports available. For example, choice of living place was an important theme mentioned in all studies although the type of accommodation varied across countries and tenancy rights were only mentioned as an issue in New Zealand. More people seemed to live with families and in group homes in Scotland when compared to England, where they availed of more independent living options with drop in support. People in Croatia specifically stated that they wanted to live in the community and not to return to institutions.

In general, although there were commonalities among the findings in relation to a perceived lack of access to basic provisions as outlined in the CRPD (e.g. article 19), it cannot be presumed they are applicable to countries with diverse social, cultural and economic conditions allied to different service systems. In fact, less salient themes identified in the national studies included self-advocacy, communication, satisfaction with staff, fear of parents dying, sexual relationships, exclusion, becoming a parent and dissatisfaction with the guardianship system.

Hence, this study is a replication of previous national surveys but with the added intention of assessing the feasibility of employing an inclusive research approach using focus groups. This seemed especially appropriate given the purpose of the research project and was in keeping with the CRPD which states that research needs to be conducted that captures the experiences of people with disability (Article 31) and that they should participate on the monitoring of the implementation of the CRPD (Article 33).

When studies are conducted inclusively, they have also raised the awareness of people with disabilities and their communities about the issues of concern to them (Garcia Iriarte et al. in press). By contrast, others have noted some unexpected effects that peer co-researchers have had, such as participants' fear of being judged by a peer interviewer or over recruitment of people with similar characteristics to the interviewer leaving out 'hard-to-reach' sectors of the population (Ryan et al. 2010). Notwithstanding some of the limitations, consultation with people with intellectual disability around the dual themes of how life was like for them at present and how life could be better is critical to the transformation of national support services in order to ensure that they are attuned more to the recipients' priorities. In this paper, we report the findings of the study, while a recently published paper gives further details of the inclusive research strategy that was adopted (O'Brien et al. 2004).

\section{Method}

The project's core group consisted of five co-researchers with intellectual disability recruited through national advocacy groups, four university co-researchers and three disability service staff, two of whom acted as supporters for the co-researchers. As a group, they 
worked together to define the issues to be addressed by the project and to formulate the main research questions, specifically 'What was life like for adult persons with an intellectual disability on the island of Ireland' and 'How could life be better?' Moreover, they jointly decided on the ways in which the inclusive research strategy would be implemented, namely through a series of focus groups across the country. Focus groups have proven suitable for use with people with intellectual disability (Gates \& Waight 2007), and they provide a number of advantages such as they are a relatively cheap way of gathering people's viewpoints and easily replicable at a regional or local level.

\section{Training}

Upon ethical approval from an Irish university, information and training sessions were run in two cities in the Republic of Ireland and one in Northern Ireland over a 2-month period to recruit and coach the coresearchers in facilitating the groups. Those who attended these sessions were recruited through contacts of the project advisory group members and from advocacy groups and services. Subsequent training sessions - up to three in all - focussed on organizing and facilitating focus groups.

\section{Co-researchers with intellectual disability}

The study engaged 20 co-researchers with intellectual disability: 14 in the Republic of Ireland and six in Northern Ireland. Two of the co-researchers were involved in two focus groups, all other co-researchers in one focus group in their locality.

\section{Study participants}

Twenty-three focus groups involving 168 people with intellectual disability were held in 10 locations in a 3-month period (16 in the Republic of Ireland, seven in Northern Ireland). Participants were recruited locally by the co-researchers through services and advocacy groups. Accessible information sheets and consent forms were distributed in advance. Available demographic data show that in total, 82 women and 83 men attended, $50 \%$ were between 18 and 30 years old, 35\% between 30 and 49 years old and $11 \% 50$ and over. Of the total number of participants, $98 \%$ were single and fewer than $10 \%$ were in employment, although upwards of $33 \%$ had experience of work. They lived in a range of settings including with family carers, in their own homes and apartments, in group homes with a small group of other persons and in residential care facilities.

\section{Focus groups}

The groups were run by a pair of co-researchers, one a co-researcher with intellectual disability and the other a university co-researcher. The number of participants in each group ranged from 3 to 20 with an average of nine people in each focus group. The format varied and was open to the pair on how best to facilitate the group. One of three formats was used: (i) the co-researcher with intellectual disability ran the focus group independently; (ii) the university co-researcher with the co-researcher with intellectual disability shared the asking of the questions; and (iii) the university co-researcher coached their partner with intellectual disability by sitting behind and giving support where reading was difficult or where responses were not forthcoming ( $\mathrm{O}^{\prime}$ Brien et al. 2014).

The groups opened by asking how life was for them: what was good and what was not so good. To prompt further discussion, a series of prompts had been identified during the briefing and training sessions with co-researchers and were used where appropriate to complement the ongoing discussion. These covered areas such as living arrangements, work, friendships, relationships, education, health and social life. The university co-researchers took responsibility for audio recording the sessions, which lasted from 45 to $60 \mathrm{~min}$.

\section{Data analysis}

All the focus group data were transcribed verbatim. A three-stage process was adopted for the data analysis with the dual aim of actively engaging the co-researchers with intellectual disability in the analysis and validation of key themes. The first stage involved open and axial coding (Corbin \& Strauss 2008) undertaken by two university co-researchers, one of whom had no previous involvement with the process. They initially cross-checked their coding for reliability across a sample of transcriptions and worked together to decipher sections that proved to be less audible by the transcriber. From their independent and joint reading of the transcripts, 19 axial themes were identified from across the majority of the 23 groups (see Table 1).

A second stage of data analysis aimed to involve the co-researchers with intellectual disability in identifying the core themes through an inclusive process of 
selective coding. Members of the core group plus other co-researchers who had participated in the running of the focus groups came together for a 3-h data analysis session 2 months after the last focus group. They were divided into two groups with ten in each. As a group, the co-researchers were presented with a short description of the 19 themes (one at a time) and given a large sheet of A3 paper with a square drawn in the centre. They were then asked to think back to the focus groups they had facilitated and what participants had said about each of the themes.

In response to the second research question, 'How could life be better?', those themes which were deemed to be more important in order to improve their lives went into the centre square, those that were less important were placed outside of it. Throughout, the group had to give reasons for their decisions and come to a joint agreement. Once all 19 themes had been placed, they were asked to consider whether some could be moved out of the square because they were not as important as others or whether any themes could be combined into one. The resulting distribution of themes from the two groups who had worked separately was then compared, and eight core themes were agreed as shown in Table 1. This form of analysis was repeated separately with a third group of eight coresearchers in Northern Ireland who identified all but money management as a core theme, which gave further evidence of consistency in the core themes as identified with the Republic of Ireland based co-researchers.

The exercise successfully involved the co-researchers in the analysis of the data that resonated with and drew on their experience as focus group facilitators. The development of a hierarchy of themes that emerged was in keeping with a grounded theory strategy (Corbin \& Strauss 2008) to determine the interconnection of themes.

A third stage consisted of university co-researchers expanding the eight core themes identified by coresearchers by providing further evidence in the form of quotes from the different focus groups. This also served as further validation of the core themes as neither of these co-researchers had been involved in data gathering or the initial data analysis. Moreover, this confirmed that data saturation had been reached. Fuller details of the overall process are given in $\mathrm{O}^{\prime}$ Brien et al. (2014).

The project was developed within a participatory framework where participation and control by people

Table I Qualitative analysis stages

\begin{tabular}{ll}
\hline Stage 1 (19 Themes) & Stage 2 (8 Themes) \\
\hline $\begin{array}{l}\text { Where and how we live } \\
\text { Work }\end{array}$ & $\begin{array}{l}\text { Becoming a house owner, flatmate } \\
\text { Becoming a paid employee }\end{array}$ \\
$\begin{array}{l}\text { Freedom [and paid employee] } \\
\text { Boyfriend /girlfriend }\end{array}$ & Becoming a partner in relationships \\
$\begin{array}{l}\text { Friendships } \\
\text { Attitudes }\end{array}$ & Becoming a respected citizen \\
Trusting & Enjoying leisure time \\
Adventure & \\
Holidays & \\
Fun and Free time & Becoming a money manager \\
Money [and paid employee] & Becoming a self-advocate \\
Advocacy and Rights respected citizen & Becoming a good communicator \\
Communication & \\
\hline Staff & \\
Family & \\
Health & \\
Looking out for Others & \\
Education \\
Death and Dying
\end{tabular}


with intellectual disability were paramount in the research process (Barnes 2003; Walmsley \& Johnson 2003). Research team members all held a strong view of disability as a human rights issue and adhered to a social model of disability (Oliver 1990). University co-researchers had previous experience of working collaboratively in research, advocacy and education with people with intellectual disability. Co-researchers with intellectual disability were recruited through selfadvocacy or research groups where they worked within a human rights-based approach, and supporters were either staff workers who supported groups of selfadvocates and co-researchers, individual's key workers or family members with an interest in respecting and promoting human rights of people with intellectual disability. Through previous personal or professional experience, they all shared a view that the rights of people with intellectual disability in Ireland were not fully respected.

The group developed a DVD with an accompanying report that summarized the findings (NIID 2010) and included the interpretation of findings from the perspective of co-researchers with intellectual disability. Co-researchers with intellectual disability suggested this type of dissemination with the aim of taking the lead in giving presentations within their local communities as well as national conference presentations.

\section{Findings}

Each of the core themes is described in turn, and their meaning is elaborated through quotations drawn from the different focus groups held which although presented sequentially were perceived by the co-researchers to be of equal importance.

\section{Living options}

Individuals held differing views regarding their satisfaction with their living situation. Some people enjoyed living where they were valuing their freedom to move around and the cost of living. For example, 'I love my home town. I can come and go and do what I want within reason and the neighbours and the whole place are nice.' (Focus group J). Others had concerns about house rules and staff control.

I'm not allowed to stay over which I really don't like but there's one bedroom apartment that people, that partners live there, I'd have the same rules applied to me. (Focus group G)
There was also a general feeling of people wanting to move from their present residence but having limited opportunities if they changed the organization where they received services, 'I do want to live outside but if I do, I can't go training.' (Focus group G). People also expressed concerns about moving to a new accommodation, such as the cost involved but also the emotional experience of moving places and the feeling of estrangement. For example, one person said in relation to the experience of moving:

Well I was used to liv[e] in the country and then I applied for a house, (...) then when I got the house, the thing that hit me the most was that my parents were ready to move me out of the home. (...) because they were around for a while, then they just stopped visiting for a while because they got sick of it. (Focus group I)

People with intellectual disability valued their privacy as an important aspect of the place where they lived, 'having my own room and my own space. Maybe some times it would be nice to have some peace and quiet.' (Focus Group K). In relation to privacy, one person mentioned that 'Parents (...) like they want to know everything like' (Focus Group I).

The experience of moving from a rural to an urban area was seen as a gain in independence for focus groups participants. They valued the freedom of using public transport and being within walking distance of amenities and shops, 'I was living out [in] the country and I was depending on lifts whereas now I can walk to the bus and up the town. It's a bit of independence for me.' (Focus Group C).

The goal of having greater independence was also voiced by those living with family carers, 'I'm still living at home but if I was to move out maybe tomorrow I would love to be able to decide: right what will I cook, what money to use.' (Focus Group G). Families, however, were perceived as not supporting the move into independent living because of an assumed lack of capacity or independence, 'My elder sister saying I wouldn't be able to look after myself, that I'm not independent enough but in ways I feel I've come on over the years, like with cooking and things like that.' (Focus Group G).

\section{Employment}

People in the focus groups valued work as an occupation and as a source of satisfaction. 
Well I worked somewhere for 5 years (...) my grandmother said to me over 10 years ago (...) 'money isn't everything in a job, it's more important being happy in the kind of work you do'. I think that's a fact. (Focus Group A)

Participants also talked about the types of jobs they liked to do, often jobs that required contact with people. Employment was also identified as a way to meet people and friends, 'I have friends at work. I used to do a catering course and I had a few friends there but I've lost touch with them.' (Focus Group E).

At an aspirational level, they identified jobs for which they should get paid on an equal basis to others. However, they faced challenges including the risk of losing benefits and the Disability Allowance (DA) which prevented them from looking seriously into employment opportunities. Among the few who had a job, there were some that were dissatisfied with the low pay they received, 'Well they can't do anything about it [the pay] because we did ask (...). We did that but it's not going to happen.' (Focus Group C).

Participants also highlighted negative attitudes when looking for employment and unsatisfactory treatment from employers at work.

\section{Relationships}

Participants expressed their wish to have relationships. For example, a focus group participant mentioned how a romantic relationship could fill in the gap due to the loss of family members,

In my experience I never had a partnership; I had my sister always all the years. When someone dear to you has gone I think everybody should have a girlfriend or a partnership to replace the one you loved. I never had a girlfriend. You would like to be happy with someone for company. (Focus Group A)

A strong feeling of agency was evident when people recalled their right to have relationships and their right to make choices about them, 'You know on the subject of boyfriend/girlfriend (...) it's a person's choice (...). No I don't think so [people have this choice]. It's our lives, it's our decisions' (Focus Group J). However, they spoke about the resistance to having relationships in the organizations where they received services, 'Because there's no girlfriends or boyfriends here, they're not ready for it, they're [kept] outside.' (Focus Group L).
Information on relationships and sex was provided at courses that some had attended. However, focus group participants identified the need for further education, 'I agree we need more information on these things [relationships and sex].' (Focus Group C). Finally, sex was usually talked about in the context of procreation and starting a family and evaluated as either a good or a bad thing. Participants did not share much about their own understanding of sex, as one said, 'information about sex is private.' (Focus Group N).

\section{Citizenship}

The theme of citizenship was the title given to issues such as choice, control and the experience of feeling included or excluded from society. People thought that others had the control over their lives, namely parents and staff. People with intellectual disability identified the tension between their need for independence and their parents' control over their lives.

You can't always live at home for the rest of your life, because say in a year's time, like say when you're 30 or 40 (..) you want to get married, like you can't be living under the same roof as your parents all the time, because say you do want kids, like you want to be able to start a family of your own, and have a house of your own, and be independent, and live on your own, but then like your parents say 'no you can't live on your own' (...). (Focus group $\mathrm{G}$ )

They understood it was their right to make choices in relation to living options, relationships and health. However, they often experienced lack of choices, 'That's the lousiest thing about it, when you go to a club you expect to be drinking even though I know some people can't, but those who can should be free to go ahead.' (Focus Group A).

Furthermore, people felt that their choices were overridden with an already scheduled programme of activities, 'then if you get staff coming in, and saying "no we can't do this because there is something else on," like shopping.' (Focus Group A). On a daily basis, people with intellectual disability identified staff as exercising control over their movements, as they assumed they, rather than the person, were being responsible for them. As shown in the following quote, this person hesitated between whose responsibility a person with an intellectual disability is, '[During lunch hour] you have to stay in the building, as staff are 
responsible for you from half eight to half three right. I shouldn't say responsible. Well you are responsible for yourself as well.' (Focus Group G). In relation to work, one person said it had to be his choice to stay home rather than going to a workshop, 'Well [I'd prefer to] stay in my house until a job came up, not have to go to a workshop.' (Focus Group A).

Choice was also spoken about in relation to people living in group homes that did not want to live there.

People also highlighted that they were at the boundaries of society, sometimes as part of it, often times outside. Taking part in activities in their locality made people with intellectual disability feel part of the community, they reported that it gave them a sense of belonging, put another way, they were seen as insiders, 'Once a week on Tuesday night we go on a social evening to a pub (...). We have a quick drink and a chat and we can have some peanuts, it's a chance for [group] to meet up with some of the locals.' (Focus Group C).

People's experiences in the community, nonetheless, could be negatively influenced by people's excluding reactions such as staring, bullying, name calling, not being addressed in conversations and being ignored. For example, 'Sometimes members of the public can be like that, if you say "hello" to them they can look at you funny! I think sometimes you can be treated differently because you have a disability.' (Focus Group A).

\section{Leisure time}

An active leisure life was important to participants. People shared that they did a variety of things alone or with others, to relax and have fun.

For the weekend I relaxed and I had loads of stuff to do but I didn't really get down to doing very much. I watched loads of tele[vision]. (Focus Group E)

They also mentioned the importance of making choices about the free time activities, doing things they enjoyed.

Making your own decision about what you do. I tell you one good thing about the centre, they do encourage you to do things more in your free time (...). I love going shopping especially for DVD's. (Focus Group A)

Going to the pub and night life were also important free time activities.
I'd like to say about my social night out on the Friday night that we go to the [pub], and if the music isn't all that great in the [pub], we go to the [hotel] and we meet friends and we talk to them and have a few drinks, but not alcohol[ic] drinks. (Focus Group D)

Leisure activities also happened in people's homes as illustrated in the following quote,

I had a good weekend. I was babysitting on Friday night and I was in [place] on Saturday. I was out in one of my work friend's house, she got engaged (...) so we just got together and had a laugh (...). Other than that, I did nothing. (Focus Group A)

They also mentioned things they did on their own, 'I listen to the radio a lot in the room and play on my accordion.' (Focus Group A).

People with intellectual disability talked about their holidays and how they spent their free time. It was felt that the holidays were very important for the people in the focus groups and there was general excitement around them. People had a good knowledge of where and when they would go on holidays or where they went in the past, ' $I$ ' $m$ going away to Spain in 3 months (...) with my mother and grandmother, I'm going for my birthday.' (Focus Group J).

People in the groups highlighted that saving was an important aspect of planning for the holidays, 'I'm trying to save up for my holidays as well this year (...). I'm going to (...) and that's a lot of money'. (Focus Group B). People, however, acknowledged their difficulties budgeting for the holidays, which links with the next theme, money management.

\section{Money management}

Participants raised several concerns in relation to money including dissatisfaction with their income and non-paid jobs, dependence created on others, the impact of employment on social security, risk in managing money and assistance with budgeting.

A common concern of participants was dissatisfaction with their income and unpaid jobs. For example,

I think if you're not working, the DA should be a lot more than it is now (...). I will say I know that I'm getting about $€ 210$ (...). To be honest, I don't 
know how anybody lives on that today. (Focus Group A)

Dissatisfaction, however, alternated with a certain degree of acceptance. For example: 'Nothing wrong with the money. Just take it as it comes.' (Focus Group B).

In this situation of low or no pay, people with intellectual disability felt economically dependent on others, for example on their family to pay their healthrelated costs:

At the moment my parents are paying $€ 47$ for $1 \mathrm{~h}$ worth of physiotherapy for me and they think that it's real[ly] expensive and they reckon that in a way it's not worth it. (Focus Group D)

Dependence on others was also expressed in relation to activities such as receiving disability benefits, 'Some of the people wouldn't be able to go to the Post Office and collect their own DA. (...) Someone like [name of person] and other house parents would have to collect it for them.' (Focus Group E).

As a group of participants, they expressed concerns around how employment would affect their entitlements.

If you work full time your allowance could be slightly affected (...) your free travel, the things you are entitled to could be taken off you so there is a little bit of a risk there! (Focus Group A)

With no or part-time employment, participants talked about the difficulty of saving, for example to go on holidays, 'And then you're told to save up, I'm trying to save up to go on holidays, and (...) to have a new house. I mean you're talking about your house, getting new stuff (...)' (Focus Group B).

The risks in managing their own money were noted, such as the possibility of being robbed, as one participant mentioned:

We had a decision there a couple of months ago; we were asked 'do we want them to collect our allowance (...)'. I said for the staff to do so for me, particularly for what I get, I wouldn't like to carry it around. Maybe in a few years time I might like to hold some of it myself. At the moment with the things you hear of people being robbed and handbags being taken, it's a good system. They know exactly what is coming in. (Focus Group A)
In all, participants were aware of the need for budgeting. This included budgets on specialist disability services and their own personal budgets to live independently.

I'd like to be able to (...) live independently, (...), I'm not good on budgeting either so that's the one thing I need help on. (Focus Group G)

The next two themes, self-advocacy and communication, were given particular prominence by the co-researchers, especially once they had identified the preceding themes and the changes needed.

\section{Self-advocacy}

Participants were keen to have their voice heard, and this was expressed in various ways, such as questioning discrimination and using authoritative figures to advocate for their rights.

Well I was annoyed because I think that the barman just said 'sorry I can't serve you' and he didn't give (...) an explanation and I think that if anything ever happens where somebody is treating you unfairly that at the very least you need to find out and have an explanation and you know why is this happening (...). (Focus Group E)

They shared experiences of bullying which seemed to be very common among the focus group participants. However, in the following case, advocacy (making a complaint) did not result in the expected outcome by the focus group participant,

A boy stayed behind in school all the time to slag me off like saying 'I was this and that' and I didn't do anything bad against him, he just picked on me and he followed me everywhere, and I told the teacher but they didn't do anything about it. (Focus Group S)

Participants also identified impediments to their advocacy. For instance, one participant felt afraid to ask staff about supporting him to attend swimming lessons, 'I use[d] to do swimming once every week in [name of place] but I didn't for a very long time and I'm afraid to ask [support staff] as she's doing a lot of work, aren't you? [looking at the support staff in the group]' (Focus Group C). 
Self-advocacy groups were discussed in terms of building confidence to speak up. Various degrees of self-advocacy were experienced within the groups. One participant stated that he was very independent and an advocate for other people, 'I'm too much independent if you like. I'm more of an advocate for other people like.' (Focus Group I). Another participant talked about the benefits of self-advocacy groups in speaking up and building confidence, 'When we started we would have been very shy (...) if you had known me 5 years ago, you would not say I'd be standing here talking to you now.' (Focus Group I). The benefits of being part of a self-advocacy group also included knowing other people, 'I meet good guys at the parliament and we became friends then.' (Focus Group I). They also identified being included in research as a way to gain confidence, 'I think we should get more experience of doing that so they gain confidence to really stand on their own feet and say we are researchers and we want to work in this way.' (Focus Group F).

\section{Communication}

People in the focus groups identified challenges in communicating with others in the community, in general, experiencing rejection and denial of their individuality, adulthood and capacity. For example, a person said that doctors often looked and talked to another person rather than the patient, 'See the doctors sometimes they don't listen to the patient, they look away and they talk to somebody else.' (Focus Group O).

A feeling of rejection was also experienced in social events, for example a person mentioned, 'Yeah when you're going out for drinks and all and you say something to them, they ignore you straight away. People are very ignorant. (...) They don't answer you.' (Focus Group P). A support person mentioned the importance of supporting people with non-verbal communication skills and provided an example of how she had supported the person to communicate.

The theme of communication was closely linked to advocacy, but the co-researchers strongly advocated for its inclusion as a main theme during the data analysis having appreciated its importance to, but separate from self-advocacy, in making change happen in their lives.

Finally, Table 1 identifies the other themes extracted from the focus group transcripts that were deemed of lesser importance or which could be subsumed under the eight core themes.

\section{Discussion}

This study was unique in a number of respects. It was conducted in association with co-researchers with an intellectual disability, it had national coverage and it documented the views as expressed by people with intellectual disability. As we have argued elsewhere, the co-researching strategy had particular benefits (O'Brien et al. 2014). Equally the study had its limitations. Participants were self-selected, and most were verbal communicators. Analysis was conducted in three stages and not all involved consultation with people with intellectual disability. Video instead of audio recording could have facilitated the review of focus groups by co-researchers with intellectual disability as others have shown and which might have allowed them to be involved in all stages of data analysis notwithstanding the big time commitment involved (Change 2010). The time gap between the actual focus groups and the analysis session made coresearchers rely on their memory to identify the centrality of themes to how their lives could be better. Furthermore, presence of support workers in some of the focus groups may have inhibited some participants to speak freely about the services they received. Equally for some participants, they formed an important support as they encouraged them to contribute to the discussion. Co-researchers with intellectual disability may have unduly influenced the core themes that were identified both in data gathering and in the analysis, although the tertiary stage of analysis by co-researchers was an additional safeguard. Further research could usefully explore supplementary themes in more detail, it could also explore their interrelationships between subgroups of persons for whom certain findings had particular salience, such as the need for better choice in accommodation and how this related to those living with family carers versus those in residential services, and finally, it could explore through explicit reflexive exercises the range of influences that co-researchers bring into the data analysis stage (Mauthner \& Doucet 2003). Even so, there was broad agreement across participants of what it means to live with an intellectual disability on the island of Ireland in the early 21st century and how their lives could be better.

The CRPD provides a useful framework to discuss the findings of this study as the eight themes identified by the co-researchers with intellectual disability are directly covered in one or more of its articles. The themes can be divided into both processes and outcomes. Process 
themes cover strategies, skills or statuses that lead to outcomes. Thus, it can be argued that being a selfadvocate, good communicator and respected citizen serves as the basis for achieving desired objective outcomes, namely being a house owner, paid employee, money manager, partner in relationships and participant of leisure activities (NDA 2010b). Although the relationship between the two types of themes was not raised specifically by the participants in the study, those on the core group who analysed the data were adamant that the findings should lead to change. They then went on to develop ways - processes - in which they could advocate for change across the areas of the findings and particularly that advocacy be recognized and funded at both local and national levels.

A major theme of the study is that people with intellectual disability lacked control over their lives with limited opportunities for decision making. As a result, they longed to be respected citizens. This theme underlies the overall aim of the CRPD but also finds a clear correlate in Article 12, Equal recognition before the law, which states that people with disabilities should enjoy legal capacity on an equal basis with others in all aspects of life. Indeed, Ireland still has to ratify the CRPD pending the reformation of capacity legislation that currently limits autonomous decision making of people with intellectual disability (Doyle \& Flynn 2013). As the findings showed, participants did not feel they had control or choice in relation to decision making leading to particular restrictions in terms of money management, living options, relationships and employment. They felt that their rights were curtailed by support staff and family members as well as by attitudes of the general population who at times regulated their public life, for example when they were refused admission to community facilities or more covertly when they were ignored, rejected or talked over. The latter links with Article 8 of the CRPD on Awareness raising, which states that awareness of the rights of people with disabilities to be treated equally should be raised among the general population.

Participants recognized the importance of selfadvocacy and their need to be good communicators so that they are able to fight for their rights, identify discriminatory practices and gain greater control of their lives. These qualities are reflected in Article 13, Access to justice which states that people with disabilities should have access to justice on an equal basis to others. However, it is possible that this finding overstates the awareness among the wider population of persons with intellectual disability of these issues as the focus group participants in this study were often drawn from advocacy groups as were the co-researchers who facilitated many of the groups. Even so, the finding that participants wished to become self-advocates serves to highlight the need to upskill people with intellectual disability into advocacy and facilitation processes that would help them to achieve the outcomes they strongly desire.

Advocacy has been embraced by groups of people with disability as part of a social movement to bring about change. In the past, people with physical disabilities have spearheaded such collective action (Barnes \& Mercer 2010). People with intellectual disability have not been at the forefront of such social movement; however, this study has led them to take up the challenge of ensuring that the findings are acted upon through the dissemination of a DVD across the island of Ireland capturing the attention of power brokers, such as Government officials and policymakers as well as CEOs of organizations.

The objective outcome themes (NDA 2010b) identified in this study not only echo the CPRD articles but also confirm those reported in previous national studies across the UK, New Zealand and Croatia (Logan et al. 2003; Emerson et al. 2005; Association for Self-Advocacy Croatia 2007): complaints of not having access to paid employment (Article 27), not being able to make decisions about their romantic relationships and a lack of relationship and sexuality education (Article 23), problems in living independently in places of their choice and with the people with whom they wanted to live (Article 19) and having access to active and inclusive leisure pursuits (Article 30).

Overall, the findings of the Irish study present on one hand, a worrying scenario for people with intellectual disability as it seems that the service systems they are currently experiencing are often not facilitating them to exercise their rights under the CRPD. Likewise, this failing presents challenges to the governmental structures responsible for the policies that accord with the implementation of the CRPD in Ireland. On the other hand, once Nation States ratify the CRPD and agree to the Optional Protocol, they have to report progress on the implementation of the CRPD 2 years following ratification and subsequently every 4 years to the United Nations. This study exemplifies that people with intellectual disability across the island of Ireland have the capacity to gather research evidence in support of reports on the implementation of the CPRD and can contribute to the submission of shadow reports by civil society. 


\section{Acknowledgements}

The authors are thankful to co-researchers with intellectual disability and their supporters, all study participants with intellectual disability, the Transfer of Knowledge Advisory Group for their work on the project and their helpful advice.

\section{Funding}

This research was funded by a Marie Curie Transfer of Knowledge Fellowship to the National Institute for Intellectual Disability, Trinity College Dublin, within the 6th European Community Framework Programme. The views expressed herein are those of the authors and not necessarily those of the 6th European Community Framework Programme.

\section{Correspondence}

Any correspondence should be directed to Edurne García Iriarte, National Institute for Intellectual Disability, Trinity College Dublin, 3054 Arts Building, Dublin 2, Ireland (e-mail: iriartee@tcd.ie).

\section{References}

Association for Self-Advocacy, Croatia, (2007) Human Rights of Persons with Intellectual Disability. Country Report, Croatia.

Barnes C. (2003) What a difference a decade makes: reflections on doing 'emancipatory' disability research. Disability and Society 18, 3-17.

Barnes C. \& Mercer G. (2010) Exploring Disability, 2nd edn. Polity Press, Cambridge.

Change (2010) Talking about Sex and Relationships: The Views of Young People with Learning Disabilities. The final report of the sexuality project by CHANGE, 2007-2010.

Corbin J. \& Strauss A. (2008) Basics of Qualitative Research: Techniques and Procedures for Developing Grounded Theory, 3rd edn. Sage, Thousand Oaks, CA.

Curtice L. (2006) How is It Going?: A Survey of What Matters Most to People with Learning Disabilities in Scotland Today. Available at: http://www.scld.org.uk/library-publications/how-it-goinga-survey-what-matters-most-people-with-learning-disabilitiesscotl (accessed on 15 November 2011).

Doyle S. \& Flynn E. (2013) Ireland's ratification of the UN convention on the rights of persons with disabilities: challenges and opportunities. British Journal of Learning Disabilities 41, 171-180.

Emerson E., Malam S., Davies I. \& Spencer K. (2005) Adults with Learning Difficulties in England 2003/4: Full Report. Available at: http://eprints.lancs.ac.uk/id/eprint/3310 (accessed on 15 November 2011).
European Union (2010) European Disability Strategy: A Renewed Commitment to a Barrier-Free Europe (2010-2020). European Commission. Available at: http://eur-lex.europa.eu/ LexUriServ/ LexUriServ.do?uri= COM:2010:0636:FIN:EN:PDF (accessed on 11 April 2013).

Garcia Iriarte E., O'Brien P. \& Chadwick D. D. (in press) Involving people with intellectual disabilities within research teams: lessons learned from an Irish experience. Journal of Policy and Practice in Intellectual Disability.

Gates B. \& Waight M. (2007) Reflections on conducting focus groups with people with learning disabilities. Theoretical and practical issues. Journal of Research in Nursing 12, 111-126.

International Association for the Scientific Study of Intellectual Disability (IASSID) (2002) Aging and Intellectual Disabilities. Available at: http://iassid.org (accessed on 15 November 2011).

Logan R., Fougere G., Hague K., Holloway L., Kiro C. \& Moore A., Percival T., \& Page-Carruth A. (2003). To have an 'Ordinary' Life. Report to the Minister of Health and the Minister for Disability Issues from the National Advisory Committee on Health and Disability. Available at: http://nhc.health.govt.nz/ archived-publications/nhc-publications-pre-2011/have-ordinarylife-kia-whai-oranga-noa (accessed on 15 November 2011).

Maulik P. K., Mascarenhas M. N., Mathers C. D., Dua T. \& Saxena S. (2011) Prevalence of intellectual disability: a metaanalysis of population-based studies. Research in Developmental Disabilities 32, 419-436.

Mauthner N. S. \& Doucet A. (2003) Reflexive accounts and accounts of reflexivity in qualitative data analysis. Sociology 37, 413-431. DOI: 10.1177/00380385030373002.

McCarron M. \& Lawlor B. A. (2003) Responding to the challenges of ageing and dementia in intellectual disability in Ireland. Aging \& Mental Health 7, 413-417.

National Disability Authority (NDA) (2010a) Advice Paper to the Value for Money and Policy Review for Disability Services Programme. Available at: http://www.nda.ie/website/nda/ cntmgmtnew.nsf/ 0/B6B630EA27AC94CC8025787F003D54F0/ \$File/Value_For_Money.pdf (accessed on 11 April 2013).

National Disability Authority (NDA) (2010b) A Review of International Outcome Measures in Disability Service Provision. Available at: http://www.nda.ie/cntmgmtnew.nsf/0/F4DC 16FB94B8D54F8025787F003F91EE?OpenDocument (accessed on 1 November 2013).

National Institute for Intellectual Disability (NIID) (2010) All We Want to Say DVD. [Video file]. Available at: http://vimeo.com/ album/166266/video/7980723 (accessed on 1 November 2013).

O'Brien P., McConkey R. \& Garcia Iriarte E. (2014) Co-researching with people who have intellectual disabilities: insights from a national survey. Journal of Applied Research in Intellectual Disabilities 27, 65-75.

Oliver M. (1990) The Politics of Disablement. St. Martin's Press, New York.

Quinn G. (2009) Bringing the UN Convention on the rights for persons with disabilities to life in Ireland. British Journal of Learning Disabilities 37, 245-249. 
Ryan L., Kofman E. \& Aaron P. (2010) Insiders and outsiders: working with peer researchers in researching Muslim communities. International Journal of Social Research Methodology 14, 49-60.

United Nations (2006) Convention on the Rights of Persons with Disabilities. Available at: http://www.un.org/dis abilities/default.asp?navid=15\&pid=150 (accessed on 6 May 2013).

Walmsley J. \& Johnson K. (2003) Inclusive Research with People with Learning Disabilities: Past, Present and Futures. Jessica Kingsley Publishers, London. 
Copyright of Journal of Applied Research in Intellectual Disabilities is the property of WileyBlackwell and its content may not be copied or emailed to multiple sites or posted to a listserv without the copyright holder's express written permission. However, users may print, download, or email articles for individual use. 